\title{
Article
}

\section{The Sense of Occupancy Sensing}

\author{
Eva Bakker ${ }^{1}(\mathbb{D})$ and Jan Veuger $2, *$ (1) \\ 1 Facility and Real Estate Management, Saxion University of Applied Sciences, 7500 KB Enschede, \\ The Netherlands; Eva.Bakker@bunge.com \\ 2 School of Finance \& Accounting, School of Creative Technology, School of Governance, Law and \\ Urban Development, Hospitality Business School \& School of Commerce and Entrepreneurship, \\ Saxion University of Applied Sciences, 7500 KBEnschede, The Netherlands \\ * Correspondence: j.veuger@saxion.nl
}

check for

updates

Citation: Bakker, E.; Veuger, J. The Sense of Occupancy Sensing. Appl. Sci. 2021, 11, 2509. https://doi.org/ 10.3390/app11062509

Academic Editor:

Alenka Temeljotov-Salaj

Received: 8 January 2021

Accepted: 22 February 2021

Published: 11 March 2021

Publisher's Note: MDPI stays neutral with regard to jurisdictional claims in published maps and institutional affiliations.

Copyright: (c) 2021 by the authors. Licensee MDPI, Basel, Switzerland. This article is an open access article distributed under the terms and conditions of the Creative Commons Attribution (CC BY) license (https:// creativecommons.org/licenses/by/ $4.0 /)$.
Abstract: Purpose: This research is about the added value of occupancy sensing and the factors that influence the added value. The objective of this research is to gain insight into the added value of occupancy sensing from a facility management perspective and the factors that influence the perceived added value. Design/methodology/approach: The paper provides insight into the added value of occupancy sensing from a facility management perspective, obtained through qualitative research. By conducting interviews with suppliers, users and an organisation that consciously chooses not to use occupancy sensing, the added value becomes apparent. The interviewed experts were approached as a result of selected articles or through the Saxion UAS network. The people who responded were interviewed. A limited number of 10 interviews was chosen because that was the minimum number of interviews required for this study. Findings: Several factors influence the added value of occupancy sensing. From the literature, these are data maturity, human behaviour and the quality of sensors. For the study, goal/motivation, preconditions and data or Information Technology (IT) were added. The interviews showed that organisations choose occupancy sensing mainly because smart buildings are on the rise, it is popular and they can make decisions based on the data and evidence. The most important precondition is that it must be known in advance what needs to be measured and that the facility managers are included in the process. The most significant influence on the success of added value is human behaviour. If the end users are not included in the new way of working, there is a good chance that they are not satisfied and that there is no added value. The functioning of IT and the use of the data also influence the added value. This research shows that added value is only achieved if the preconditions are met and factors such as human behaviour are taken into account. When this works well, facility management as a department will also be able to deliver substantial value to the entire organisation. Research limitations/implications: The limitations of this research were that there was only one interview with a non-user. Their opinion would be more valuable where the respondents are asked more about the data maturity of the organisation and their alignment with the organisation's strategy. The limitations mainly have to do with the limited time frame of the research. In further research, it is also indicated that for a more complete study, this time frame should be extended. Practical implications: The results can be used by everybody who needs to get insight into the use of occupancy sensing from a facility management perspective and the added value for facility management. Originality/value: While there is a significant amount of literature on occupancy sensing and the use of sensors in office environments, there is only limited research on the added value of occupancy sensing from a facility management perspective. Paper type: Research paper. The literature review shows that the added value of facility management is difficult to make tangible. Many organisations see facility management as a cost item, and therefore, the costs must always be taken into account. There is a shift from cost to added value for the organisation, but this only works if the strategy of facility management (FM)/corporate real estate management (CREM) is aligned with the strategy of the organisation. In many cases, this does not yet appear to be the case. For future research, the advice is to look more into other smart features and their added value. Data maturity is a limitation of this research, and the relationship between data maturity and facility management should be studied more. The future is digital and data-driven, and there are not sufficient studies on that. 
Keywords: sensing; occupancy; added value of facility management

\section{Introduction}

The development of the internet changed facilities and the built environment. Technologies and research disciplines enable the internet to reach out into physical objects is called the Internet of Things (IoT) [1]. The range of physical objects that are connecting to the internet is growing, and the world is becoming smart. With various definitions and meanings, smart is defined by Medina-Borja [2] as 'a system capable of learning, dynamic adaptation, and decision making based upon data received, transmitted, and processed to improve its response to a future situation. The system does so through self-detection, self-diagnosing, self-correcting, self-monitoring, self-organizing, self-replicating, or selfcontrolled functions. These capabilities are the result of the incorporation of technologies for sensing, actuation, coordination, communication, control, etc.' The more recent development of the Internet of Things (IoT) in smart buildings is even more important with blockchain [3-5]. Smart buildings are equipped with smart systems. Smart materials, sensors and metres within buildings gather data about building operation and management [6]. There are smart systems for maintenance, security, lighting, occupancy, energy and indoor climate. Smart systems offer an opportunity to support processes in the building, use resources more efficiently and contribute to attuning the building to changing demands [7].

Smart features interact with one another and the building users. The operational phase of a building is the most prolonged period of the life cycle of the building and is often managed by the facility department. The definition of facility management (EN 15221) is 'the integration of processes within an organisation to maintain and develop the agreed services which support and improve the effectiveness of its primary activities'.

This research focuses on the benefits of smart systems for facility managers and the users of an office building. Reducing energy consumption and improving building efficiency are two reasons why companies choose smart systems [8]. The occupancy of a building has an enormous influence on the energy used in a building [9]. With sensors, the occupancy of the building can be measured. This provides insight into not only the energy use of the building but also the occupancy and building use of the users. With the data from the sensors, the organisation can optimise space management for buildings. Space management is critical because efficient use of space can reduce square metres and can lead to a better fit between workspace design and the tasks of the users [10]. The data from the sensors give insight into the employee work patterns regarding office rooms and areas. This can be used to make decisions about office layouts [11].

Numerous companies supply smart sensors. Verdantix is an independent research and consulting firm with a focus on innovative technologies. It conducted a global study [12] on the suppliers of smart software and the best fit for customers. The study is based on live demonstrations and a survey with 16 market-leading suppliers. They also conducted interviews with facility managers from 15 companies to understand customer needs. The study on space management features concluded that there is a push to maximise the employees per building and that space management is an essential factor to buy smart software. Respondents said that software for space planning is already used. However, the current software gives insufficient data to support management decisions, and it is very precious to perform analysis.

The study by Vendantix shows that there are gaps between the demand and the supply of the software. The exploitation is not optimal, and this implies that the potential benefits of occupancy sensing for the different users are not fully achieved in practice and that smart systems do not always deliver what they promise. This fuels the suspicion that the enthusiasm to adopt smart building features may be hype-driven and a form of corporate branding. Therefore, the objective of this research is to get insight into the added value of occupancy sensing of offices from the facility management perspective. 


\section{Literature Review}

\subsection{What Is the New Role of Facility Management?}

Digitalisation is changing the role of the facility manager. New technologies are making the facility manager more a data provider who does know everything about the workspace. The prediction is that the facility manager will add value to all stages of the user interaction and is more about people performance and management [13]. The advantage of this development [14] is that the facility manager can make decisions based on data and facts instead of experience. The introduction showed that the European standard definition for facility management is 'the integration of processes within an organisation to maintain and develop the agreed services which support and improve the effectiveness of its primary activities'. As the definition says, facility management supports the primary process. Facility management, therefore, does not directly contribute to the profit of an organisation. Moreover, there is always pressure to show added value and to do more for less. It is always driven by the aim to reduce and control cost and find new ways to organise and manage the supporting services for a company [15], because it is initially considered to be predominantly a cost item. The perceived focus of facility management on the physical environment itself undervalues the impact on the most critical organisational resource: the people who use the workplace to produce value for the business [16]. However, the facility management world is changing. Cost reduction is no longer the number-one priority, but companies recognise that facility management can actively add value to them by facilitating attractive workplaces that attract new employees [15].

Although the importance of facility management is increasing, and there is a shift from a cost centre to added value for an organisation, it remains challenging to define added value and make that added value tangible. Over 50 definitions of added value were established in a study by Jensen et al. [17]. For instance, the added value of real estate can be defined as 'the contribution of real estate to organisational performance and the attainment of organisational objectives from the point of view of different stakeholders' [18] Because facilities involve costs and investments, the added value for facility management and corporate real estate management (CREM) can be defined as 'the trade-off between the benefits and the costs and risks to achieve these benefits' [15]. De Vries et al. [18] identified value types as productivity, profitability and competitive advantage. Den Heijer [19] later added sustainability as an added value. Jensen et al. [15] distinguished six different types of added value:

1. Use value

2. Customer user value

3. Economic, financial or exchange value

4. Social value

5. Environmental value

6. Relationship value

It was confirmed that the concept of added value is interpreted in different ways and linked to various topics. The prioritisation of the different added value types is subjective and dependent on the participant [20]. In their study on how added value is used in management practice, he used 10 types of added value that are obtained from the FM value map [20]. Table 1 shows the 10 types of added value and whether they have an impact on the core business or the surroundings. Because there are many added values and the interpretation is subjective, these are the added values that are used for this research. 
Table 1. Added value types [20].

\begin{tabular}{|c|c|c|c|}
\hline No. & Added Value & Explanatory Memorandum & Impact On \\
\hline 1 & Satisfaction & $\begin{array}{l}\text { The impact of facility management (FM) } \\
\text { or corporate real estate management } \\
\text { (CREM) on the satisfaction of customers, } \\
\text { staff/end users and owners }\end{array}$ & Impact on the core business \\
\hline 2 & Cost & $\begin{array}{l}\text { Operational cost, staff turnover and } \\
\text { capital investments }\end{array}$ & Impact on the core business \\
\hline 3 & Productivity & $\begin{array}{l}\text { Efficiency, low staff absence and } \\
\text { effectiveness }\end{array}$ & Impact on the core business \\
\hline 4 & Reliability & Business continuity, security and safety & Impact on the core business \\
\hline 5 & Adaptation & Foresight, flexibility and responsiveness & Impact on the core business \\
\hline 6 & Culture & $\begin{array}{l}\text { Organisational identity, corporate image } \\
\text { and corporate brand }\end{array}$ & Impact on the core business \\
\hline 7 & Social & Income, commerce and tax & Impact on surroundings \\
\hline 8 & Economical & Employment, education and integration & Impact on surroundings \\
\hline 9 & Spatial & $\begin{array}{l}\text { Architectural expression, landscaping } \\
\text { and townscape }\end{array}$ & Impact on surroundings \\
\hline 10 & Environmental & $\begin{array}{l}\text { Resource consumption, pollution and } \\
\text { environmental sustainability }\end{array}$ & Impact on surroundings \\
\hline
\end{tabular}

The added value of, for example, service can be made visible with service-level agreements (SLAs) or key performance indicators (KPIs) with a minimum level of customer satisfaction. If customer satisfaction gets higher than the minimum level of customer satisfaction, an increase in use value will appear. In other words, an increase in use value will occur if the customer satisfaction over time gets higher than the minimum level of customer satisfaction. There is no mandatory change in the SLA, but an added value is created.

\section{Strategic Alignment}

'High-quality, cost-effective facilities and related support services are an essential foundation for any business; but a workplace that has a demonstrable impact on measures of organisational effectiveness like workforce attraction and retention and business productivity is also vital in communicating the value of FM in the corporate world' [16]. To achieve organisational objectives, the facility and real estate objectives must be derived from the overall corporate goals and ambitions. Figure 1 [20] shows that the strategy development process is a process in which the client organisation and the FM department interact, allowing room for proactive advice from the FM department.

The added value of alignment between organisational performance and FM/CREM performance can be illustrated with the use of the input $->$ output $->$ outcome $->$ addedvalue chains [20]. For example, a new workplace layout (input FM/CREM) -> more knowledge sharing (output FM/CREM) -> more innovation, improved image (outcome organisation) -> added value. Royal Institution of Chartered Surveyors (RICS) published a paper on facility management. It discovered that there is a shift of FM/CREM from a cost centre to a business partner that actively contributes to the achievement of the organisation's objectives. However, the profession is still mainly seen as a cost centre. FM/CREM performance is still focused on cost control, and the role of the facility manager is about operational efficiency despite the potential of the strategic impact on organisational performance. 


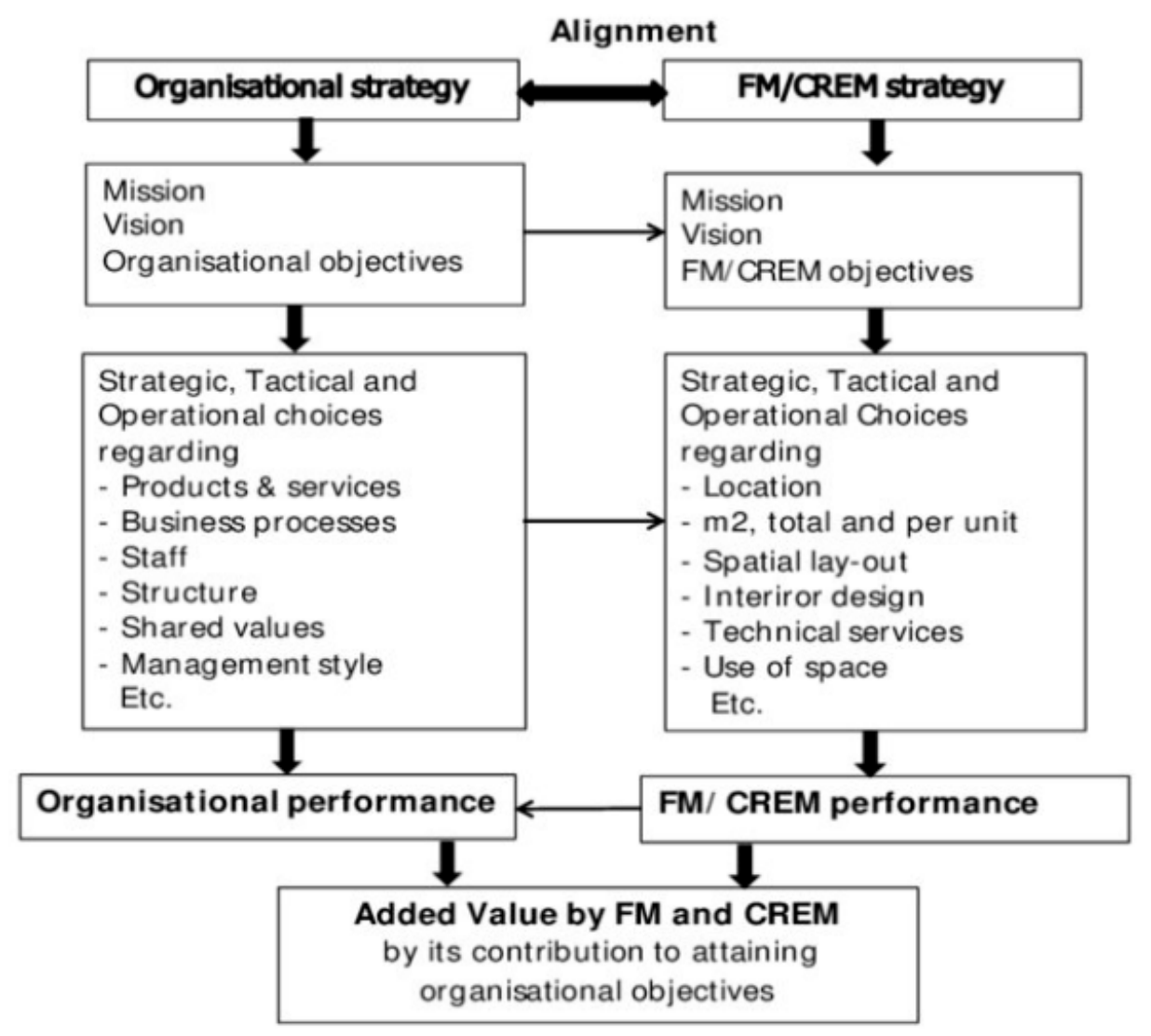

Figure 1. Alignment organisational strategy with the FM/CREM strategy [21,22].

\subsection{Workplace Management}

The primary purpose for most facility managers is providing a suitable workspace. This involves (the determination of) requirements, design, construction, adjustment if the demand changes and acquisition or disposal. Benchmarks for facility performance are expressed as a ratio to floor space. This implies that by reducing floor space, everything becomes more efficient [23]. Modern economic and social developments lead to a demand for more flexibility in space planning for the workplace [24]. However, through space management, the performance of every individual and the organisation as a whole is affected. Decisions about the layout, facilities and the way of working all affect employee satisfaction and productivity [25]. This implies that increased cost savings by applying different ratios may lead to a negative impact on other value domains. As the cost of staff, in general, is between $70 \%$ and $80 \%$ of operating costs, by leverage a negative impact on satisfaction or productivity has an impact. Hassanain and Abdul Moied [26] built a model to divide workplace management (space management) activities into several steps. It starts with identifying the organisational structure and then planning for allocation of space, allocating the space, collecting data and evaluating the space used. The last step in the model is a management report on the current level of space utilisation. What happens after that step is the central question of this research.

\subsubsection{Occupancy and Space Utilisation}

Office space utilisation is the number of people using a space in a building [27]. It is the ratio between people and capacity. It can be used to identify the current and potential future use of space. Measurements of these competencies can be used as indicators for a new space. The rate of office space utilisation data is associated with:

- Occupancy rates: The division between the use of space and the amount of space available

- Frequency: Duration or frequency of use of a room over a particular period [28] 
There are different methods to measure space utilisation. There is a possibility to physically count the people on a location at a specific time, or companies can use occupancy sensors. Facto [29] published a white paper on how to make a building smart. The greatest benefit of smart building technology is achieved mainly with buildings still to be developed. With a new building, the facility management department must be involved from the start. The first step is to define a shared vision with all the involved parties. Existing buildings can also benefit from smart technologies. Many features can be added to the existing technologies and systems in a building. The main focus point for implementing smart features in a building is that there must be a widely supported ambition of the owner and the user. With the use of modern techniques such as sensors, apps and data analysis systems, facility management can develop from a reactive to a proactive department and focus even more on the customer and the service.

\subsubsection{Occupancy Sensing}

Occupancy sensing is a sensor-based methodology for enabling automatic activation of facility management services. That methodology is based on survey occupancy within the different rooms of a building. This is measured with people's presence through the interpretation of data from ultrasonic sensors. Surveying occupancy is possible with a network of sensors with lasers, image processing analysis, ultrasonic waves and temperature and pressure gradients [30]. Each of the options has limitations, depending on the monitoring scope and context. For example, infrared sensors might be unreliable because of double-counting. This can be caused by incorrect frequency settings or reflection on materials (shadows) when the camera lens is soiled. They tend to undercount people. Thermal-based sensors are more expensive and can be disrupted by the current climate conditions when surveyed. Pressure-based sensors must be positioned in a certain way to enable proper counting. Past experiences with these applications do not seem to be completely integrated and automated. The information exchange between a building and its occupants is not optimal [31]. An extensive literature review by Ahmad [31] showed that no single method or sensor is identified that best estimates and solves the problem of occupancy information. The applications that are used are not always capable of exchanging data with the building management system and/or users. The expectation is that in the future, highly accurate methods are presented from the research community [31].

\subsection{Factors That Influence (the Perception of) the Added Value of Occupancy Sensing}

This research focuses on the added value of occupancy sensing for offices and the factors that influence the perceived added value. The added value of occupancy sensing can be that spaces that remain empty can be scaled down and being secluded. This leads to more efficient use of the room because cleaning is less needed intensively, lightning and climate control can be switched off there and better maintenance in the short and long term can be adjusted to the actual use of the spaces. This is pleasant for the user but can also save on real estate and service costs [32]. If the data results are not exploited well, and the organisation does not know how to reach the full potential with the systems, the effects can be adverse. Proper space utilisation is not always a critical factor for good space management practice, and therefore, the (utilisation) data are not always useful. The following reasons why it does not work are examples from professionals [33]:

- Measures of utilisation provide information but not solutions.

- High utilisation rates do not mean that space is managed effectively.

- Collecting data costs time and money, and the data can be difficult to interrogate and analyse.

- Utilisation survey results may not be integrated with space need assessments or timetabling or linked with other management information systems.

- It is often used on a relatively small part of the total floor area.

- There is an overflow of options and therefore data.

- There are privacy issues. 
From the literature, it seems that three factors are conditional for successful occupancy sensing: data maturity of the client organisation, human behaviour and the quality of the sensors. These will be discussed next.

\subsubsection{Data Maturity}

With the rapidly growing technological smart developments, many companies feel the pressure to implement these smart technologies to not fall behind the competition. However, they are often unable to change the way they work, which means that the systems are not used in the best-possible way [34]. Data maturity shows to which extent an organisation is capable of the utilisation of the data it generates [35]. The data maturity of an organisation can be divided into different phases or levels. Figure 2 shows the different levels defined by Spruit and Pietzka [36]. The abbreviation MDM stands for master data management, which can be defined as 'the management of the consistent and uniform subset of business entities that describe the core activities of an enterprise'. To create a competitive advantage of data, the data must be readily available and up to date. This seems common sense, but especially more significant companies battle with the enormous amount of data and have no fitting strategy to exploit the data [37].

\begin{tabular}{|l|l|}
\hline Level & Description \\
\hline 1. Initial & $\begin{array}{l}\text { A first awareness fir issues regarding the } \\
\text { topic } \text { N.MM has been rase on a operaticnal } \\
\text { level. Initial steps are initialized. }\end{array}$ \\
\hline 2. Repeatable & $\begin{array}{l}\text { Measures form individuals are conducted } \\
\text { to solve individual problems. No connec- } \\
\text { tion to other units or projects. Still opera- } \\
\text { tional. }\end{array}$ \\
\hline 3. Defined process & $\begin{array}{l}\text { First collaborations take place on a tactical } \\
\text { level. Awareness was created for the exist- } \\
\text { ence of other initiatives. }\end{array}$ \\
\hline 4. Managed and measurable & $\begin{array}{l}\text { Best practices are in place for handling } \\
\text { MDM. The are defined process on a tactical } \\
\text { level. }\end{array}$ \\
\hline 5. Optimized & $\begin{array}{l}\text { Optimized handling of MDM. The organi- } \\
\text { zation's efficiency has been improved. Tac- } \\
\text { tical approach on the topic. }\end{array}$ \\
\hline
\end{tabular}

Figure 2. Data maturity levels [36].

In organisations at an initial level of data maturity, the organisations know the area of master data and who is using which data. In contrast, at an optimised level, employees are not reluctant to use specific systems to obtain data in all available possibilities [37]. Optimised organisations make data-driven decisions or evidence-based decisions instead of intuition, which leads to better organisational performance [38]. The data maturity of an organisation thus also determines the success of occupancy sensing. Organisations with a low data maturity level will most likely have more difficulty in achieving added value with occupancy sensing than organisations that can use occupancy sensing to make data-driven decisions.

\subsubsection{Behaviour}

A study by Labeodan [39] showed that human behaviour is an additional limitation for successful use of occupancy sensing. The results of occupancy sensing can be that some spaces are never or not optimally used. From that moment on, facility managers have to deal with the human factor in building management. An essential aspect of occupancy sensing is the behaviour of the users. Occupancy behaviour refers to all actions of occupants that affect building energy consumption [40]. Activity-based working is 
a way of working that a growing number of organisations adopt. In an activity-based working environment, employees do not have their own workstations, but the workstations are open plan areas with open meeting spaces, concentration rooms and meeting rooms [41]. Activity-based working encourages employees to do different work activities like collaboration, concentration and creativity in spaces that are designed to support those activities [42].

A study by Leesman [42] on activity-based working and satisfaction showed that the desk rotation rate is not sufficient. They found that $71 \%$ of the respondents stay at one desk for the whole day. Another study [43] showed that employees do not like to lose their own workplace and that, for them, it feels like a loss of company culture. Even though a company arranges all facilities for activity-based working well, it often does not work optimally in practice. People like to have firmness and are attached to a personal place and security. They do not want to look for a place every morning, and prefer to have their personal desks with their personal things. This also ensures that in some cases it has no added value at all to measure the use of space, because even though some parts of the building may be used less, the people who are always sitting there will be very dissatisfied if that part is closed off [43].

The above studies show that despite excellent facilities, people do not make optimal use of the new way of working, because they like to stick to their own habits. Mansaray [44] showed that between $50 \%$ and $70 \%$ of planned organisational changes do not work, because people do not like change. They are afraid that they lose privileges and opportunities they enjoy, and start resisting. Research shows that leadership is crucial to successful organisational change. The leadership of change is about managing and directing the stages of change as well as the emotionalism connected with those changes. If that is executed well, people are more likely to embrace the change and the new way of working. The importance of change management in combination with the relationship between employee satisfaction and productivity shows why it is essential that the human side be included in the process and contributes to the success of occupancy sensing.

Although steering and changing people is often complicated and time-consuming due to their behaviour, it is already happening with things like parking and crowd management. Due to the growing population, towns, streets and schools are becoming overcrowded [45]. Different systems on the market gather data about the number of people in a specific area [46]. This is important to prevent disasters with stampedes and overcrowding. Sensors are used for sensing and measuring the state of a crowd and often include microphones, cameras, smartphones and also social media. Next to the data, there is also a crowd interpretation provided by experts to decide on adequate crowd intervention.

In the case of the parking management, occupancy sensing is used to detect empty parking lots. The sensors and the systems behind them take account of weather conditions, changes in light, moving vehicles, persons and other objects. A side effect of measuring with various smart systems is that for many people, it is still an invasion of their privacy. Besides, as mentioned earlier, people's behaviour also ensures that the systems are not always used optimally [47]. If the users of the systems did not have to deal with privacy or annoying people, the system to control the use of space could have looked very different. If people had been more like boxes in a warehouse, it could have worked much better.

The products in modern warehouses are tagged with an Radio-Freguency Indetification (RFID) tag. These products can be identified wirelessly using radiofrequency. The products can be tracked throughout the entire period in the warehouses during all the different processes. Nowadays, no human involvement is needed for order picking, because it all goes automatically through the tags. This way, no human errors are made, and there are always real-time data available [48]. RFID tags are used by people to, for example, clock hours and access certain areas of the office. They can also be used so that people can find one another, but this still results in many discussions about privacy. The use of RFID tags for assets and products can generate benefits without too many privacy issues. However, tagging employees through uniforms, identity documents, bracelets and 
anklets can raise privacy issues that might be better circumvented by choosing a different way of working [49].

\subsubsection{Quality of Sensors}

Teixeira [50] conducted a study on the methodologies to monitor people count. They found discrepancies from $5 \%$ to $22 \%$ compared to manual counting. This is an old study, and the methods are probably better now, but this shows that sensing is not always that accurate. Meyn et al. [50] showed a model that gathered data with cameras and $\mathrm{CO}_{2}$ sensors that reduced the variance of occupancy from $70 \%$ to $11 \%$. It is [51] advise to use sensors based on ultrasonic waves for monitoring occupancy within a building. These sensors are easy to use and install, but the data handling is not that easy. Labeodan et al. [39] (2015) reviewed the existing conventional systems that are utilised in buildings for occupancy sensing. They showed that obtaining information is often challenging because of human behaviour and the limitation of tools. The review showed that chair sensors are an excellent system to measure occupancy. A 2020 study on building occupancy measurement systems [52] compared different systems on the merits and limitations. They reviewed cameras, WiFi-based sensors, infrared sensors, $\mathrm{CO}_{2}$ sensors and electricity metres. The study showed that the fusion of sensors tends to perform the best because different sensors can compensate for each other. The before mention authors predicted that current developments like 5G and artificial intelligence (deep learning technologies) will be a significant addition to occupancy sensing and the use of sensors.

\subsection{Insight into Literate Review}

It appears from the literature that from a facility management perspective, it is not always easy to demonstrate the added value. As a facility manager wishing to use occupancy sensing successfully, they must take the organisation's objectives into account. There are also influencing factors such as data maturity, the behaviour of people and the quality of the sensors. Because occupancy sensing is still under development, not much has been written about it yet. The use of smart features to improve the use of buildings and space has been much described but more from a sustainability perspective. This is understandable because the government has a strong focus on sustainable entrepreneurship and also introduces laws and regulations with which the organisations must comply. Implementation is a complicated process, and to achieve added value, it is essential that the facility manager be involved in the process from the beginning and that there be a shared vision among the shareholders of the project.

The literature review gives insight into the theory and relevant models. The focus of this study is on the added value of occupancy sensing and the factors that influence the perceived added value from a facility management perspective. To illustrate the expected findings of the research, a conceptual framework was developed. The conceptual framework shows how the different variables are expected to relate to one another. The added value can only be achieved if all factors are taken into account. The influential factors that emerged from the literature review are the goal/motivation to use occupancy sensing, data maturity of the client organisation, human behaviour and quality of the sensors (data and Information Technology). The expectation is that other preconditions also influence the added value of occupancy sensing. That is why conditions have been added to the conceptual framework. The preconditions will be looked at from a supplier and a user perspective. The corresponding research questions are elaborated in the next section.

\section{Research Methodology}

\subsection{Research Question}

The literature review shows that the perceived added value of occupancy sensing has not reached its full potential. The objective of this research is to find out what the added value is from a facility management perspective and what the factors are that influence that added value. Based on the introduction and the literature review, two research questions 
were formulated: (1) What factors influence the perception of the added value of occupancy sensing? and (2) what is the added value of occupancy sensing from a facility management perspective? Based on the research question the following objective was formulated: To gain insight into the added value of occupancy sensing from a facility management perspective and the factors that influence the perceived added value.

\subsection{Sub-Questions}

To answer the research questions, these were broken down into sub-questions. The sub-questions were formulated with the help of the conceptual framework and the essential influences on the added value of occupancy sensing from a facility management perspective.

Sub question 1: Why do facility managers/companies use occupancy sensing, and what is their goal?

To gain insight into the effect of occupancy sensing, it is essential to know why companies use occupancy sensing. The added value can be measured by whether a goal is achieved or not achieved, so is it an essential first question for this research.

Sub question 2: What are the preconditions for successfully using occupancy sensing?

The literature review shows that there are various preconditions for the success of occupancy sensing. If the start is not right, the capacity will never be used optimally. This question will be answered from an organisational and from a supplier perspective.

Sub question 3: Does occupancy sensing change the behaviour of end users?

The literature review shows that people's behaviour is difficult to control. With the use of occupancy sensing, companies want to control people in order to improve the use of space. That is why it is essential to include behaviour in this research into the added value of occupancy sensing. This question also looks into the privacy issues that might occur with the use of occupancy sensing.

Sub question 4: How useful are the data recorded for space management purposes? What factors may limit using the data to their full potential?

The data maturity of an organisation shows whether the organisation can use the generated data properly. This question shows whether an organisation uses the data to influence the use of space.

\subsection{Research Strategy and Design}

To answer the research question, occupancy sensing is viewed in different ways from a facility management perspective. The research within this research is an evaluation study. Evaluation research is the systematic assessment of the worth or merit of time, money, effort and resources spent in order to achieve a goal [32]. The strategy that fits this research is qualitative research. It will provide insight into the values, experiences and perceptions of the respondents and thereby contribute to the insight into the added value of occupancy sensing. The opinions of the respondents are more accessible to obtain from interviews than from quantitative surveys, and therefore qualitative research fits the objective for the study the best. The research will provide information about the current strengths and weaknesses of occupancy sensing from a facility management perspective. The best-fitting approach for this research is deductive. [21]. The research will give insight into the possible effects of occupancy sensing on the usage of space for facility managers and users. The literature has fuelled the suspicion that the use of occupancy sensing has not yet reached its full potential. A deductive approach is used to test this suspicion and to find out where the cause may lie.

\subsection{Operationalisation}

The definition of operationalisation is 'the translation of concepts into tangible indicators of their existence' [53]. The critical concept that is operationalised are influencing factors of the added value. The literature review shows that the influencing factors can be 
divided into different aspects. Table 2 shows the factors obtained from the literature and the related aspects.

Table 2. Operationalisation.

\begin{tabular}{lll}
\hline & Motivation/goal & $\begin{array}{l}\text { Smart building } \\
\text { Organisational objectives }\end{array}$ \\
\cline { 2 - 3 } Influencing factors & Data maturity \\
& Preconditions & $\begin{array}{l}\text { Quality of the sensors } \\
\text { Other preconditions }\end{array}$ \\
\cline { 2 - 3 } & Human behaviour & Privacy \\
& Behaviour \\
\hline
\end{tabular}

The interviews' themes were formed with the different aspects related to the key concepts in combination with the conceptual framework.

\subsection{Data Collection Techniques}

The questions were answered using interviews. Interviews are useful for getting the story behind the respondents experiences with occupancy sensing. This research aimed to gain insight into the added value of occupancy sensing from a facility management perspective. Lindholm [28] and Jensen and van de Voordt [52] also used interviews in their research on the added value of facility management and reached impressive results. Interviews give the respondents room to give an opinion and create a good picture of reality. The interviews were conducted on the basis of a topic list). The topic list was based on the conceptual model, which was based on the literature review, with the addition of the role of the facility manager and future developments. They were semi-structured interviews using Microsoft Teams, in which the respondents were given the space to talk about the topics in detail. The interviewer made adjustments if the conversation deviated too much from the topics. Three different groups were interviewed for the research. The sample had a variation to get a holistic understanding of the topic. The plan was to include three suppliers, two companies that consciously do not use occupancy sensing and five that do use occupancy sensing. The companies were recruited using a convenience sampling technique.

The suppliers provided insight into the preconditions and the data. The second group is companies that have deliberately chosen not to use occupancy sensing. They provided insight into the preconditions for a company to decide whether to opt for occupancy sensing. The third group is the most critical because these are companies that use occupancy sensing. They answered questions on the actual effect of occupancy sensing in practice. A total of 10 interviews were conducted. The interviews were conducted in a way that data saturation was reached. Because the interviews were about experiences, it is always possible that more insight was obtained with multiple interviews. However, with the current results, it is possible to draw a consistent line. Because all sub-questions can be viewed from different angles, the topics in all interviews are the same. Although the group that does not use occupancy sensing did not generate any data, it is interesting to know what the motivation is concerning the data. In this way, a complete picture is sketched. The original plan was to interview three suppliers, five users and two non-users. In total, four suppliers, five users and one non-user were willing to cooperate with this research. As a result, the perspective of the non-user is not entirely representative. The deviations in the research will be discussed further in the Discussion section.

What is important to add is that the research was carried out at the time of the Coronavirus Disease (COVID-19) pandemic. This caused most people to work from home and changed the working method for the research. All the interviews were carried out online or by telephone. The quality of the content of the interviews did not change, because they were not face-to-face interviews. If they had been physical interviews, the dynamics between interviewer and respondent might have been different, but for now, this did not 
cause any inconvenience. On the contrary, it saved much time for both parties, and that time has now been put into the development of this research.

\subsection{An Independent Analysis}

All interviews were recorded and fully transcribed. For coding, the topic list and a code tree based on the literature review to which additional open codes were added to. The interviews were transcribed and can be found in Appendices 4 until 13 of the original research. Quotes from the interviews were used for the results. The quotes were translated, and the number of the respondent and the group were added with the timestamp of the quote. Suppliers are S, users are U and the non-user is NU. Because it is translated, the context may have changed slightly. The original statements can be found in the transcripts. It was agreed with the respondents that they will continue to remain anonymous. They all were given a number in the transcripts. In the elaboration of the interviews, they were named as user, supplier or non-user. Who they are or what kind of organisation they work for did not make any difference. The researchers knew what information came from whom, and can give an explanation, if necessary. All transcripts are in Dutch.

\section{Results}

The results are described per sub-question, and the main questions are answered in Section 5. The sub-questions arose based on the literature review and the resulting conceptual framework. The literature review showed that certain factors influence the added value of occupancy sensing, and therefore, this section is structured as follows: goal/motivation, preconditions, human behaviour and data/IT. To find the added value of occupancy sensing from a facility management perspective, respondents were also asked directly what they think the added value is. This is discussed in the last part of this section.

\subsection{Motivation and Goal}

The literature review showed that part of the added value consists of expectation/ agreements and whether those expectations/agreements are achieved. If companies start using sensors, they have certain expectations, and if those expectations are not achieved, added value will never be achieved. The added value from facility management is also strongly related to the goals of the organisation and the alignment between the organisation and the facility department. The first step of a process is a goal or motivation, which is why it was important for the research to know what the goal or motivation of an organisation is to start using sensors. The sub-question for this topic was, Why do facility managers/companies use occupancy sensing, and what is their goal? Suppliers were also asked with what purpose or motivation the customers usually come to them. The non-user was also asked why they consciously choose not to use sensors.

\section{Conclusions}

This sub-question aimed to provide insight into why companies choose occupancy sensing. The ultimate goal for every facility decision is to deliver added value to the organisation. This can be in the areas of cost, satisfaction, productivity, reliability, adaptation, culture, social, economic, spatial and environmental, as described by Jensen and van der Voordt [52]. The literature review also showed that the added value of facility management could be made transparent by utilising input-output-outcome. If the theory is linked to the respondents' answers, it shows that facility management decisions are still primarily taken from a cost perspective. The data are often used to generate evidence and to demonstrate to management how costs are saved. However, the data are also used to create a more practical layout and use of business premises and, therefore, can also be linked to the productivity aspect of the possible added value. In addition to effectiveness, the data can also contribute to employee satisfaction. By supporting change processes and providing insight into the use of spaces, the data can also contribute to employee satisfaction and, therefore, productivity. The literature review fuelled the suspicion that many organisations 
choose smart buildings and smart features because they can increase the value of their premises and improve their image. This research shows that this is also how it is done. Suppliers, in particular, indicated that many organisations who want a smart building are joining them. From a user perspective, it is also indicated that branding can be an essential motivation for using smart features. In that case, smart features are the input from FM/CREM, and image improvement and attracting new employees more efficiently are the outcome and therefore added value.

The environmental aspect is also crucial because the government puts much pressure on specific sustainability goals. However, research shows that this is not the primary motivation for the interviewed organisations to use smart features and occupancy sensing. The role of the facility manager is changing, and the prediction is that in the future, the decisions will be primarily data-based. In that case, smart features are used to support the primary activities of the facility manager. The expectation is that the human side will always remain relevant and that it will be the task of the facility manager to find the right balance in this. The interview with the non-user showed that the goals for occupancy can also be achieved in other ways, and for them, it is a cost they do not want to invest in.

\subsection{Precondition}

For a project to succeed, there are always certain preconditions with which it must comply. Usually, factors such as time, money and quality lay the foundation for success. To see what the added value of occupancy sensing is or can be, it is essential to gain insight into the basics. The following conditions emerged from the literature review: data maturity of the client organisation, human behaviour and quality of the sensors. The expectation was that the supplier and the users would provide other valuable information about essential preconditions. Therefore, the sub-question for this topic was, What are the preconditions for successfully using occupancy sensing?

This question is answered from a supplier perspective and a user perspective. The suppliers know different customers, and the users can provide insight through their practical experience with the use of occupancy sensing. The answers from the respondents about the preconditions can be divided into two phases of occupancy sensing: the preparation phase and the operational management phase. The preconditions are therefore arranged within these two phases. The question is first answered from the supplier perspective and then from the user perspective. What is interesting about the sample is that the user-respondents were at very different stages in the use of occupancy sensing. One of the users was still very much in the beginning and was still determining the scope, and another user has been using occupancy sensing for years. The conversations with the users in different stages make it possible to look at the situation from multiple angles. The market is very much in development, and what did not work last year may now be resolved. Answering this sub-question will be completed by linking supplier and user and any gaps discussed before.

\section{Conclusions}

It appears that suppliers and users unanimously agree that an essential precondition for successful use of occupancy sensing is that it is known precisely what needs to be measured and what results the organisation wants to achieve. Knowing what one wants to measure is enhanced by a firm strategic alignment between the FM strategy and the corporate strategy and translation of this into concrete actions and targets at tactical and operational levels in the organisation. This indicates that more data-mature organisations will be better equipped to meet this precondition and the less data-mature organisations will have trouble defining the information needs as they lack a plan-do-check-act system and dashboard monitoring for their daily operations. From the user side, it is essential to take the time to look for a suitable supplier. From the supplier side, it is crucial to get all relevant stakeholders at the table in the first phase in order to ensure the system meets the demands of those that will use it. Of course, the interviewed suppliers did not say anything about this, but it appears from the users that not all suppliers can deliver what they say. 
That is why it is also essential to accurately record what is expected of the supplier and what has to be delivered.

\subsection{Human Behaviour}

Literature research showed that the human factor is often a failure factor in the successful use of smart features, including occupancy sensing. To look at the added value of occupancy sensing, it is therefore also essential to look at the human factor and especially the influence on people and their behaviour. The sub-question for this topic was, Does occupancy sensing change the behaviour of end users? The users were asked how they experience or have experienced the human influence, and the suppliers were asked how they deal with behaviour and how they can advise the customer about this. The literature review revealed three factors that influence the human side and, therefore, the added value of occupancy sensing. These are behaviour, change management and privacy. This question focuses mainly on the users, but because the suppliers have much practical experience, they can also provide useful insights into people's behaviour and its consequences.

\section{Conclusions}

Research shows that occupancy sensing can change the behaviour of the end users. Occupancy sensing can improve the use of a building and make it a lot easier for the employees. On the other hand, it has to be used properly. The literature and interviews show that the human factor is a critical success factor. The technology is relatively new, and people find that difficult and even threatening. The moment an organisation involves the employees into the process and removes the uncertainties, even the most reluctant people will be able to make it. On the other hand, there are also organisations for which occupancy sensing does not work. The management must be behind it; if not, it will never succeed. This is also the reason why the non-user interviewed does not choose to use occupancy sensing. They know that they will not be able to convince the organisation and that it is, therefore, a waste of investment. Occupancy sensing may decrease workplace costs or provide a more efficient way of working. However, when employees are entirely dissatisfied and, therefore, less productive, those savings are quickly reversed and can only cost more in the long run.

\subsection{Data and IT}

To make good use of technology, users must know how it works; otherwise, it does not pay off. The theory shows that people who have to extract concrete actions from the data do not always know exactly how it works or what the data say. That is why the sub-question for this topic is, How useful are the data recorded for space management purposes? What factors may limit using the data to their full potential? In line with the other sub-questions, this question can be answered from a supplier and a user perspective. The suppliers might not give insight into their shortcomings, but they will give insight into how the data are used by the users.

\section{Conclusions}

This section shows that with the help of the suppliers, the generated data are quite useful, but there are still quite a few factors that hinder the proper use of the data. These include the use of multiple systems, no one responsible for it and technical problems. Two things stand out. The first is that the user and the supplier indicate that the data are often available, but not much is done with the data. This shows that not enough data are being used to control the system, and not enough data-driven decisions are being made. The second thing that stands out is that the suppliers indicate that everything is technically possible but that the users say that this was not the case and that certain links could not be made. The role of the facility manager is essential in the handling of the data. If the added value of facility management is not embedded in the organisation, the importance of the data for the whole organisation is not recognised and therefore the data are not used 
at their full potential. The output of the data will then not be seen as important and will eventually be neglected.

\subsection{Added Value}

The study aimed to gain insight into the added value of occupancy sensing and the factors that influence the added value. To get a complete picture, respondents were asked what they thought the added value of occupancy sensing was.

Data-based decisions

Just as it was the goal for many, it turns out to be the added value; data should be used to make decisions based on facts rather than assumptions or gut feeling. Complaints or questions should be answered through consultation and on gut feeling. This can be done much better if data-driven. Then the decision makers can say, 'This is simply shown by the data, and then you can act on it' (S1, 00:27:06). The question remains whether the evidence is used to justify the facility service or whether it is used to provide added value to the entire organisation.

Satisfaction and productivity

For many organisations, the data from occupancy sensing help with the satisfaction and, therefore, the productivity of the employees. 'Then they just look at the map or on their app and see where it is quiet. Then they can just work there quietly. Then that person is more satisfied, and his productivity is higher' (U5, 00:19:57).

Effectiveness

In the end, it is always about the money, but many organisations use occupancy sensing to divide the spaces more effectively. In some cases, they can even divest or rent properties. This saves money in the long term, but from a facility management perspective and the definition of the field, it is mainly about supporting and organising processes more effectively and efficiently. Occupancy sensing can help with that by making users aware, 'so they also feel more responsible for their reservation and show up or cancel the meeting room on time so someone else can use the room. As a result, it is no longer necessary to rent externally. Some customers see how little space is used so that they can rent out to their customers again' (S3, 00:21:00).

\section{Conclusions}

This study aimed to gain insight into the added value of occupancy sensing from a facility management perspective and the factors that influence the perceived added value. This goal was formulated because there was a suspicion that occupancy is not used as its full potential and that the facility manager has to deal with that. There were two research questions formulated for this research: (1) What factors influence the perception of the added value of occupancy sensing? and (2) what is the added value of occupancy sensing from a facility management perspective?

\subsection{Influencing Factors}

The factors that influence the perception of the added value of occupancy sensing are the goal/motivation, conditions, human behaviour and the use of data/IT. The goal or motivation to start with occupancy sensing has an influence on the added value. The literature review showed that the added value of facility management is hard to show and that it is essential that the FM/CREM strategy be aligned with the strategy of the organisation. There is a shift from a cost-based approach to an added-value approach, but in practice, it appears that this shift has not yet been made in many organisations. This also explains why, for most respondents, the purpose of occupancy sensing is to be able to use the data as evidence. This way, they can show management how much they save and how efficiently they work. Within the development of the FM organisations from reactive to proactive, generating evidence is still a reactive way of working. However, the data can be used to do better analysis and predictions. This allows the facility manager to take up the role of a proactive business partner. 
An additional motivation for using occupancy sensing is that the insight can be used to set up rooms more efficiently. At the moment that the rooms are set up more efficiently, the respondents also want to use the data to support the employees in their work and give them insight into the use of the space. In this way, a change process can be supported, and employees are more satisfied and, therefore, more productive. Some organisations want to improve their image and brand and use occupancy sensing to contribute to this. This was the suspicion before the research started and was confirmed by the interviews. Finally, for many organisations, the sustainability aspect is a reason to use occupancy sensing. However, it appears that this is not the main reason. The use of smart features is changing the role of the facility manager; the prediction is that in the future, the decisions will be primarily data-based. In that case, smart features can be used to support the primary activities of the facility manager. They can help improve the professionalisation of FM in an organisation and the level of control. The literature review showed that data maturity, human behaviour and the quality of the sensors are also factors that influence the added value of occupancy sensing. The prediction was that there were additional conditions, so that was the topic of the second sub-question.

The most important precondition for generating added value is that it must be known in advance what exactly needs to be measured and what the organisation wants to know. This can be done based on a complaint or issue. A strong alignment between the FM strategy and the organisational strategy contributes to the insight into this precondition. As a result, there is a good chance that organisations that are more data-mature will be able to meet this precondition more easily. Organisations that are less data-mature and are not aligned with the corporate strategy have more trouble with this because of the more reactive way of working. From the supplier side, it is essential to involve the relevant stakeholders from the beginning in the process to make sure supply and demand are aligned. From the user side, it is crucial to take time to find the most suitable supplier and define the requirements, because the study shows that not every supplier can deliver what the user wants. The literature review showed that the behaviour of the end users could influence the added value of occupancy sensing. An added value of occupancy sensing is the more efficient use of a building. This is beneficial for the employees, but the employees must know that it is also an added value for them. Occupancy sensing stimulates a different way of working, and using that success takes time, and it is essential to guide the end users in that process. Human behaviour is that influential on the added value of occupancy sensing that if it is neglected, there will never be any added value, and it is a waste of investment.

With the help of the supplier, the data can be shown on useful dashboards. The facility manager can use the dashboards to optimise the use of the building or to adjust the services to the behaviour of the end users. The fail factors are the use of multiple systems, technical problems and the lack of responsibility for the use of the data. The role of the facility manager is essential in the handling of the data. If the added value of facility management is not embedded in the organisation, the importance of the data for the whole organisation is not recognised, and therefore, the data are not used at their full potential. The suppliers imply that technically everything is possible but that the human factor obstructs this. The users imply that the suppliers cannot deliver everything they want. This is because not all the systems can connect, and that has to be developed.

\subsection{Added Value}

Jensen and Van der Voordt [52] defined 10 types of added value for FM/CREM: satisfaction, cost, productivity, reliability, adaptation, culture, social, economic, spatial and environmental. The added value of occupancy sensing for the respondents focused mainly on satisfaction, cost, productivity and culture (image). Research shows that the added value of facility management is challenging to show because it is mainly seen as a cost item. From a facility management perspective, the added value of occupancy sensing is that they data can be used to set up the building more efficiently, offer employees more insight and 
create data-based decisions that allow them to work more proactively. The added value of occupancy sensing can contribute to the insight into the added value of facility management in an organisation. However, this can only be achieved if the factors mentioned earlier are taken into account. Smart features are still under development, but the expectation is that data will become even more critical in the future. When the FM/CREM department is well aligned with the strategy of the organisation, a facility manager with data-based facility management can have a significant impact on the functioning of the entire organisation. Research shows that to get added value from occupancy sensing, many conditions must be fulfilled. The non-user showed in the interview that not every organisation can comply with those conditions, and therefore it is not a sustainable investment.

\subsection{Discussion}

The conclusion shows that occupancy sensing is regularly used as window dressing, which prevents the facility manager from getting the full potential out of it. It is used to improve the image of the organisation, and therefore, there is no focus on other possible benefits that occupancy sensing could generate. However, if this is taken into account, it is important that the right shareholders be involved in the process from the outset to ensure that the benefits are achieved for everyone.

It is essential to think about the operation phase and who should manage it from the start with this type of project. Research shows that facility management is not always seen as a priority. It is still mainly seen as a cost item, and therefore, facility managers use the data as a means of accounting for their work. There would be remarkably more profit made if the data could be used to steer the processes proactively. The definition of facility management states that a facility manager is always busy improving the processes and the entire organisation benefits from this. This research focused on occupancy sensing, but it applies to all smart features.

What is striking is that fail factors are things that, at first sight, seem logical and are taken into account as a matter of course. However, research shows that it is often difficult for organisations to manage these factors. Especially the human factor should not be underestimated because it can counteract the added value when it is not included in the process.

It turns out that occupancy sensing can add value to the facility manager. The data are used for better building, and they also really contribute to employee satisfaction. High employee satisfaction can also lead to higher productivity [38], which is beneficial for the facility manager, who often has to deal directly with complaints. The data can enhance the strategic position of FM. In the best-case scenario, FM is data-driven in a strategic position. However, the availability of data can help FM professionals to strengthen their strategic role and can thus contribute to the further professionalisation of the profession.

The facilities professionals know that if FM is not aligned with the values and mission of the organisation, it can never deliver added value in a sustainable way [53]. Unfortunately, this is not known by the organisations themselves, and it is up to the facility department to show this priority. That is precisely why the non-user chose not to use occupancy sensing. The non-user knows that they are not in a strategic position within the organisation to address people about the way they work and that management does not support any agreements. Therefore, the investment in occupancy sensing is not profitable.

This research started with the benefits of a smart feature but ended on a larger scale with the importance of the role of the facility manager within the organisation. The moment an organisation identifies facility management as a cost item, proving and utilising the added value of occupancy sensing will be much more challenging to achieve than the moment the data can be used to steer the entire organisation efficiently.

\subsection{Limitations}

Even though this research may contribute to the use of occupancy sensing in practice, there are some limitations to this research. The use of interviews proved to be an excellent 
way to generate the right information, but it would have been better for the research if a second data collection method had been added. The scope of the research was clear, but it turns out that the subject is more significant than previously expected. By looking at the position of FM, the scope was enlarged and became more than just the added value of occupancy sensing. Care had to be taken during the research that the study did not become too broad and that the focus remained on occupancy sensing.

The limitation of the sample size was that there was only one interview with a nonuser. Better insight into the disadvantages of occupancy sensing would have been obtained if more interviews with organisations that consciously choose not to use occupancy sensing were conducted. This would complement the insight into the current market. Besides, the quality of the sensors and the type of sensors used by organisations were not discussed in depth during the interviews. However, this was an essential factor that emerged from the literature review. In addition, the data maturity of the organisations was not questioned. It would also have been better for the study if there had been a discussion with an organisation that was ahead in the field of smart features and where the entire office was smart. It would also have been an addition if the researchers could visit the locations to get a good picture of the current situations and the added value. However, this was not possible in connection with the COVID-19 pandemic.

Another limitation of the study was that the native language of the researchers is Dutch, and the interviews were also conducted in Dutch. After the interviews, the results were translated into English. It is possible that with this translation, information was lost or was interpreted differently. To limit this, it was all checked by someone whose native language is English. However, there may be some difference in the information.

To ensure reliability, respondents were interviewed in a location that was comfortable for them. Because of the COVID-19 pandemic, the respondents were interviewed mainly digitally from their homes. Additionally, to ensure reliability, the topic list was sent to the respondents beforehand, and they were immediately asked whether all topics were clear. In this way, the respondents knew in advance what the topics would be, and this could also be prepared by the respondents. The limitation of qualitative research and interviews remains that the results are based on the interpretations of the researchers. To limit this, quotes from the transcripts were used instead of the interpretations of the researchers from the interviews themselves.

The validity could be improved, many of the same answers were given but this could be generalised. Therefore, the results would have to be tested again. The validity was threatened because the research group was a limited sample of the total population regarding occupancy sensing. The respondents work for a limited number of types of organisations. The interviews were anonymous, but the type of organisations they work for did influence the results. Due to a lack of time, respondents from different organisations were not actively searched for, but to be able to generalise, this would have been better.

In the end, the researchers had to deal with different people who had different opinions. The added value of facility management remains an intangible concept, and many factors influence it. That is why there is still plenty more research to be done on this subject. The recommendations for further research from the researchers are described in Section 6.

\section{Future Research}

For now, the research focused on four suppliers, five users and one non-user. It would be a significant next step to test and possibly validate the results of this research with a larger group of users and suppliers. Even though a reasonably unambiguous pattern emerges from the research, a validation round will still be able to generate new insights. Many of the users interviewed were still at the beginning of the sensor adoption process. It would be interesting to talk to them again in a year and ask them how they are doing. What are the developments, what are the lessons learned and how would they approach it now? 
It will also be an excellent addition to interview people who are still in doubt about using occupancy sensing. If insight is gained into the reason why there are doubts or the thresholds that currently exist, a complete picture can be obtained. This is beneficial for users, suppliers and other facility professionals.

The research showed that it is common for users to feel that there is too little space in a building, while FM professionals, due to occupancy research, indicate that there are peak occupancy levels. Therefore, future research into the relationship between real-time visibility of utilisation and customer satisfaction could help facility managers and end users with this problem. A study on the impact of data-driven FM on the position of FM in an organisation will enhance the knowledge about the position of FM and the enablers of that position. Therefore, it would be a step forward from this research. Additionally, it will also be interesting to see what kind of sensor best suits data-driven facility management. This is practical research but does provide useful information for the field. This research focused on occupancy sensing, but there are, of course, many other smart features that can be researched similarly, for example, the use of robots or Quick Response Code (QR codes) to measure satisfaction. The development of smart features is fast, and data-driven facility management is growing. It is the future of facility management, and there will be a lot to investigate.

Author Contributions: Conceptualization, E.B.; methodology, E.B. and J.V.; software, E.B..; validation, E.B. and J.V.; formal analysis, E.B.; investigation, E.B.; resources, E.B. and J.V.; data curation, E.B.; writing — original draft preparation, E.B. and J.V.; writing — review and editing, J.V.; visualization, E.B. and J.V.; supervision, J.V.; project administration, E.B.; funding acquisition, J.V. All authors have read and agreed to the published version of the manuscript.

Funding: This research received external funding.

Conflicts of Interest: The authors declare no conflict of interest.

\section{References}

1. Zaslavsky, A.; Jayaraman, P.P. Discovery in the Internet of Things. Ubiquity 2015, 2015, 1-10. [CrossRef]

2. Medina-Borja, A. Editorial Column-Smart Things as Service Providers: A Call for Convergence of Disciplines to Build a Research Agenda for the Service Systems of the Future. Serv. Sci. 2015, 7. [CrossRef]

3. Veuger, J. (Ed.) Blockchain Technology and Applications; Nova Science Publishers Inc.: New York, NY, USA, 2019.

4. Lehavi, A.; Levine-Schnur, R. (Eds.) A Database Exploring Blockchain and Real Estate in Disruptive Technology, Legal Innovation, and the Future of Real Estate; Springer International Publishing: New York, NY, USA, 2020; pp. 3-25.

5. Veuger, J. (Ed.) Blockchain Technology and Applications II; Nova Science Publishers Inc.: New York, NY, USA, 2020.

6. Zhao, Q. Research opportunities arising from control and optimization of smart buildings. Control. Theory Technol. 2017, 15, 78-80. [CrossRef]

7. Abdallah, M.; El-Rayes, K. Multiobjective Optimization Model for Maximizing Sustainability of Existing Buildings. J. Manag. Eng. 2016, 32, 04016003. [CrossRef]

8. Pašek, J.; Sojková, V. Facility management of smart buildings. Int. Rev. Appl. Sci. Eng. 2018, 9, 181-187. [CrossRef]

9. Chen, Z.; Jiang, C.; Xie, L. Building occupancy estimation and detection: A review. Energy Build. 2018, 169, 260-270. [CrossRef]

10. Vischer, J. Strategic work-space planning. Manag. Rev. 1995, 37, 33.

11. How IoT Reinvents Space Management in Smart Buildings. Available online: https://behrtech.com/blog/how-iot-reinventsspace-management-in-smart-buildings / (accessed on 16 June 2020).

12. Green Quadrant Integrated Workplace Management Systems 2019. Available online: https://www.ibm.com/downloads/cas/ 9LV6ML7B (accessed on 16 June 2020).

13. Is the Future of Facility Management as Bright as We Would Like to Think? Available online: https://www.linkedin.com/pulse/ future-facility-management-bright-we-would-like-think-ankerstjerne/ (accessed on 16 June 2020).

14. Xue, Y.; Temeljotov-Salaj, A.; Engebo, A.; Lohne, J. Multi-sector partnerships in the urban development context: A scoping review. J. Clean. Prod. 2020, 268, 122291. [CrossRef]

15. Jensen, P.A. Theoretical Model Demonstrating the Value Adding Contribution of Facilities. In Proceedings of the European Facilities Management Conference, Hotel Okura, Amsterdam, The Netherlands, 16-17 June 2009.

16. Raising the Bar: From Operational Excellence to Strategic Impact in FM. Available online: http://www.buildingclouds.com/ docs/Raising_the_Bar_3_Full_Report_240317_IC.pdf (accessed on 16 June 2020).

17. Jensen, P.A.; van der Voordt, T.; Coenen, C. (Eds.) The Added Value of Facilities Management: Concept, Findings and Perspectives; Polyteknisk Boghandel og Forlag: Lyngby, Denmark, 2012. 
18. De Vries, J.C.; De Jonge, H.; Van Der Voordt, T.J. Impact of real estate interventions on organisational performance. J. Corp. Real Estate 2008, 10, 208-223. [CrossRef]

19. Den Heijer, A. Managing the University Campus-Information to Support Real Estate Decisions. Ph.D. Thesis, Technical University of Delft, Delft, The Netherlands, 2011.

20. Jensen, P.A. The Facilities Management Value Map: A conceptual framework. Facilities 2010, 28, 175-188. [CrossRef]

21. Saunders, M.; Lewis, P.; Thornhill, A. (Eds.) Research Methods for Business Students; Pearson Education Limited: Harlow, UK, 2007.

22. Jensen, P.A.; Van der Voordt, T. (Eds.) Facilities Management and Corporate Real Estate Management as Value Drivers: How to Manage and Measure Adding Value; Routledge: London, UK; New York, NY, USA, 2017.

23. Hoxha, V.; Tore, B.; Bjorberg, S.; Temeljotov Salaj, A. Developing sustainable energy efficient buildings - a transnational knowledge transfer experience between Norway and Kosovo. Stud. High. Educ. 2018, 45. [CrossRef]

24. Best, R.; Langston, C.; de Valence, G. (Eds.) Workplace Strategies and Facilities Management; Elsevier: Oxford, UK, 2003.

25. Becker, F.; Kelley, T. Offices at Work: Uncommon Workspace Strategies that Add Value and Improve Performance; Wiley: Hoboken, NJ, USA, 2005.

26. Hassanain, M.A.; Abdul Moied, M. A Process Modeling Approach to Space Management in Corporate Organisations. Built Hum. Environ. Rev. 2011, 3, 49-59.

27. The Utilization of Office Spaces and Its Impact on Energy Use. Available online: https://pdfs.semanticscholar.org/b5c2/b219f3 fed71bbecfbe25924d56f31c98334a.pdf (accessed on 16 June 2020).

28. Lindholm, A. A constructive study on creating core business relevant CREM strategy and performance measures. Facilities 2008, 26, 343-358. [CrossRef]

29. Smart Buildings-Wat Is Het? En Hoe Maak je Een Nieuw of Bestaand Gebouw Smart? Available online: https:// form.facto.nl/ sites/default/files/downloads/facto_whitepaper_smart_buildings.pdf (accessed on 16 June 2020).

30. Kuutti, J. A Test Setup for Comparison of People Flow Sensors. Licentiate Thesis, Aalto University, Espoo, Finland, 2012.

31. Ahmad, J.; Larijani, H.; Emmanuel, R.; Mannion, M.; Javed, A. Occupancy detection in non-residential buildings-A survey and novel privacy preserved occupancy monitoring solution. Appl. Comput. Inform. 2020. [CrossRef]

32. Bhat, A. Evaluation Research. Available online: https://www.questionpro.com/blog/evaluation-research-definition-methodsand-examples/ (accessed on 16 June 2020).

33. Rigter, J.; Smetsers, T. Slim Omgaan Met Smart Buildings. 2016. Available online: https://arrangegroup.nl/nieuws/slimomgaan-met-smart-buildings (accessed on 16 June 2020).

34. Buitelaar, R. Building the Data Driven Organisation. 2018. Available online: https://theses.liacs.nl/pdf/2017-2018BuitelaarRuben.pdf (accessed on 16 June 2020).

35. MHR Analytics. The Five Stages of Data Maturity. Available online: https://www.mhranalytics.com/data-maturity/operational/ (accessed on 16 June 2020).

36. Spruit, M.; Pietzka, K. MD3M: The master data management maturity model. Comput. Hum. Behav. 2015, 51, 1068-1076. [CrossRef]

37. Davenport, T.H.; Prusak, L. Working Knowledge: HOW Organizations Manage What They Know; Harvard Business Press: Cambridge, MA, USA, 2000.

38. Brynjolfsson, E.; Hitt, L.M.; Kim, H.H. Strength in Numbers: How Does Data-Driven Decision-making Affect Firm Performance? SSRN Electron. J. 2011. [CrossRef]

39. Diego Blanco Cadena, J.; Moretti, N.; Poli, T.; Re Cecconi, F. Low-cost sensor network in cognitive buildings for maintenance optimisation. TEMA Technol. Eng. Mater. Archit. 2019, 5, 93-102.

40. Kjærgaard, M.B.; Lazarova-Molnar, S.; Jradi, M. Poster Abstract. In Proceedings of the 2015 ACM Sixth International Conference on Future Energy Systems, Bangalore, India, 14-17 July 2015; Association for Computing Machinery (ACM): New York, NY, USA, 2015; Volume 15, pp. 215-216.

41. Hoendervanger, J.G.; Ernst, A.F.; Albers, C.J.; Mobach, M.P.; Van Yperen, N.W. Individual differences in satisfaction with activity-based work environments. PLoS ONE 2018, 13, e0193878. [CrossRef]

42. The Rise and Rise of Activity Based Working; Leesman: London, UK, 2017.

43. Brunia, S.; Hartjes-Gosselink, A. Personalization in non-territorial offices: A study of a human need. J. Corp. Real Estate 2009, 11, 169-182. [CrossRef]

44. Mansaray, H.E. The Role of Leadership Style in Organisational Change Management: A Literature Review. J. Hum. Resour. Manag. 2019, 7, 18. [CrossRef]

45. Wijermans, N.; Conrado, C.; Van Steen, M.; Martella, C.; Li, J. A landscape of crowd-management support: An integrative approach. Saf. Sci. 2016, 86, 142-164. [CrossRef]

46. Shalash, W.M.; Al Hazimi, A.; Al Zahrani, B. A Mobile Based Crowd Management System. Int. J. Adv. Res. Comput. Com 2017, 6, 205-215. [CrossRef]

47. Dasgupta, A.; Gill, A.Q.; Hussain, F. Privacy of IoT-enabled smart home systems. In IoT and Smart Home Automation [Working Title]; IntechOpen: London, UK, 2019; pp. 1-11.

48. Lee, G.; Ryu, W.; Hong, B.; Kwon, J. Smart warehouse modeling using Re-recording methodology with sensor tag. In Communications in Computer and Information Science; Springer International Publishing: Amsterdam, The Netherlands, 2011; Volume 186, pp. 193-200. 
49. Radio Frequency Identification (RFID) in the Workplace: Recommendations for Good Practices. Available online: https: //www.priv.gc.ca/media/1956/rfid_e.pdf (accessed on 16 June 2020).

50. Facility Management EN 15221 and ISO 41000. Available online: https:/ / www.en-standard.eu/facility-management-en-15221and-iso-41000/ (accessed on 16 June 2020).

51. Meyn, S.; Surana, A.; Lin, Y.; Oggianu, S.M.; Narayanan, S.; Frewen, T.A. A sensor-utility-network method for estimation of occupancy in buildings. In Proceedings of the 48h IEEE Conference on Decision and Control (CDC) held jointly with 200928 th Chinese Control Conference, Shanghai, China, 15-18 December 2009; IEEE: Piscataway, NJ, USA, 2009; pp. 1494-1500.

52. Jensen, P.A.; Van der Voordt, T. Adding value by FM: Exploration of management practice in the Netherlands and Denmark. In Proceedings of the European Facility Management Conference EFMC, Berlin, Germany, 4 June 2014.

53. Salaj, A.T.; Gohari, S.; Senior, C.; Xue, Y.; Lindkvist, C. An interactive tool for citizens' involvement in the sustainable regeneration. Facilities 2020, 38, 859-870. [CrossRef] 